\title{
Lipase-Catalyzed Ring-Opening Polymerization of Substituted Lactones
}

\author{
Hirofumi KIKUCHI, Hiroshi UYAMA, and Shiro KOBAYASHI ${ }^{\dagger}$ \\ Department of Materials Chemistry, Graduate School of Engineering, Kyoto University, \\ Kyoto 606-8501, Japan
}

(Received June 24, 2002; Accepted September 5, 2002)

\begin{abstract}
Effects of substituted position and ring size of methyl-substituted lactones in their lipase-catalyzed polymerization have been systematically investigated. In the polymerization of 6- and 7-membered lactones using Candida antarctica lipase as catalyst, the reaction behaviors of $\alpha$-substituted lactones were relatively similar to those of the unsubstituted ones, whereas much lower enzymatic polymerizability was observed in the case of $\omega$-substituted lactones. The enzymatic polymerization of $\gamma$-methyl- $\varepsilon$-caprolactone also proceeded under mild reaction conditions and the reaction rate was close to that of $\varepsilon$-caprolactone. In the polymerization of $\alpha$-methyl-substituted macrolides (13- and 16-membered), the polymerizability decreased by the introduction of the methyl substituent. The enzymatic polymerizability of these lactones was compared with their anionic polymerizability using sodium methoxide as initiator. In case of all the $\alpha$ - or $\omega$-substituted lactones examined, the lower anionic polymerizability was observed than that of the unsubstituted ones. These data indicate that the polymerization behaviors strongly depended on the lactone ring size and substituent position as well as type of catalyst (initiator).

KEY WORDS Enzymatic Polymerization / Lactone / Lipase / Polyester / Ring-Opening Polymerization /
\end{abstract}

Ring-opening polymerization of lactones has been extensively studied, since it provides a facile synthetic route of biodegradable polyesters with controlled structure and molecular weight. ${ }^{1}$ So far, a variety of catalysts have been developed for the precise polymerization of lactones. Recently, lipase has received much attention as new catalyst for production of biodegradable polyesters. ${ }^{2}$ Lipase catalyzed ring-opening polymerization of unsubstituted lactones in various ring-sizes under mild reaction conditions, yielding high molecular weight polyesters. ${ }^{3}$

Furthermore, lipase catalysis exhibited unusual polymerizability of lactones in comparison with that of conventional chemical catalysts. Our recent report showed that macrolides possessed much lower reactivity in the polymerization catalyzed by zinc octanoate than $\delta$ valerolactone (1a) or $\varepsilon$-caprolactone (2a). ${ }^{4}$ In the $P$ seudomonas fluorescens lipase-catalyzed polymerization, on the other hand, the reverse tendency was observed. ${ }^{5}$ This is due to the stronger recognition of the macrolides by lipase catalyst.

So far, there have been many studies concerning ring-opening polymerization of various 4-membered substituted lactones by chemical catalysts. ${ }^{1 \mathrm{a}}$ Lipase also induced the polymerization of such lactones, ${ }^{6}$ and the enantioselection took place to give optically active polyesters under selected conditions. ${ }^{6 b, 6 \mathrm{~d}, 6 \mathrm{e}}$ In contrast, the ring-opening polymerization of sub-

${ }^{\dagger}$ To whom correspondence should be addressed. stituted lactones of other ring sizes using chemical catalysts has little been reported. For example, $\alpha$-n-propyl- $\delta$-valerolactone and $\delta, \delta$-dimethyl$\delta$-valerolactone showed no polymerizability using sodium catalyst. ${ }^{7}$ Aluminum isopropoxide catalyst polymerized $\varepsilon$-heptanolactone (2c), however, its polymerizability was much smaller than that of $\mathbf{2 a} .{ }^{8}$ This may be due to steric effect of the substituent on the monomer coordination site in the catalyst.

As to the enzymatic polymerization of substituted lactones in the ring size larger than six, we have briefly reported that $\alpha$-methyl-substituted medium-size lactones, $\alpha$-methyl- $\delta$-valerolactone (1b) and $\alpha$-methyl$\varepsilon$-caprolactone (2b), were efficiently polymerized by Candida antarctica lipase (lipase CA). ${ }^{9}$ From the optical purity of the residual monomer, it was found that no enzymatic enantioselection occurred. On the other hand, $\omega$-methyl-substituted 6-membered lactone, $\delta$-caprolactone (1c) showed very low homopolymerizability toward lipase $\mathrm{CA},{ }^{6 \mathrm{e}}$ although the enantioselection of $1 \mathrm{c}$ took place in the lipase CA-catalyzed copolymerization of 1c with 2 a or with 12-dodecanolide (3a), yielding optically active polyesters. Fluorinecontaining lactones were also enantioselectively polymerized by lipase CA catalyst. ${ }^{10}$

In order to systematically examine the enzymatic polymerizability of unsubstituted and substituted lactones, we have performed the lipase-catalyzed polymerization of various substituted lactones. Furthermore, the enzymatic polymerizability of these lactones 


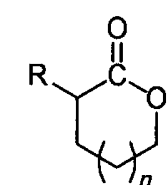

1a: $\mathrm{R}=\mathrm{H}, n=1$

1b: $\mathrm{R}=\mathrm{CH}_{3}, n=1$

2a: $\mathrm{R}=\mathrm{H}, n=2$

2b: $\mathrm{R}=\mathrm{CH}_{3}, n=2$

3a: $\mathrm{R}=\mathrm{H}, n=8$

3b: $\mathrm{R}=\mathrm{CH}_{3}, n=8$

4a: $\mathrm{R}=\mathrm{H}, n=11$

4b: $\mathrm{R}=\mathrm{CH}_{3}, n=11$

\section{Chart 1.}

has been compared with that by an anionic initiator.

\section{RESULTS AND DISCUSSION}

\section{Lipase-Catalyzed Polymerization of Substituted Lac- tones}

In this study, seven methyl-substituted lactones have been used as monomer for the enzymatic ringopening polymerization: 1b, 1c, 2b, 2c, $\gamma$-methyl$\varepsilon$-caprolactone (2d), $\alpha$-methyl-12-dodecanolide (3b), and $\alpha$-methyl-15-pentadecanolide (4b) (Chart 1). The polymerization of the substituted lactones was carried out by using lipase catalysts with different origin in bulk at $60^{\circ} \mathrm{C}$. The catalysts used in this study were lipases derived from Candida antarctica (lipase CA), Candida cylindracea (lipase CC), Mucor miehei (lipase MM), Pseudomonas fluorescence (lipase PF), and porcine pancreas (PPL). These lipases were reported to show high catalytic activity for the polymerization of unsubstituted lactones. Especially, lipase CA possessed a very high catalytic activity toward the polymerization of $\mathbf{2 a},{ }^{11}$ yielding the polymer of high molecular weight. ${ }^{3 \mathrm{~b}}$ Polymerization results are summarized in Table I. Molecular weight of the polymer was estimated by size exclusion chromatography (SEC) using tetrahydrofuran (THF) as eluent.

Lipase CC and PPL showed no catalytic activity for the polymerization of all the substituted lactones examined. The substituted medium-size lactones were polymerized by only lipase CA. In the polymerization without enzyme (control experiment), the monomer was recovered unchanged, indicating that the substituted lactones were polymerized through the lipase catalysis. The monomer conversion of $\omega$-methyl-substituted lactones (1c and 2c) was lower than that of $\alpha$-methylsubstituted ones (1) and $\mathbf{2 b}$ ), yielding the product with much lower molecular weight. In the polymerization of $\mathbf{1 b}$, the polymer of the molecular weight higher than $1 \times 10^{4}$ was obtained (entry 1 ). The polymerization result of 7-membered $\alpha$-substituted lactone (2b) was sim-
Table I. Lipase-catalyzed ring-opening polymerization of substituted lactones $^{\text {a }}$

\begin{tabular}{|c|c|c|c|c|c|}
\hline Entry & Monomer & Enzyme & $\frac{\text { Conv. }^{b}}{\%}$ & $\frac{M_{\mathrm{n}}^{\mathrm{b}}}{\times 10^{-3}}$ & $M_{\mathrm{w}} / M_{\mathrm{n}}^{\mathrm{b}}$ \\
\hline $1^{\mathrm{c}}$ & $1 b$ & lipase CA & 74 & 11 & 1.9 \\
\hline 2 & $1 b$ & lipase MM & 0 & & \\
\hline 3 & $1 b$ & lipase PF & 0 & & \\
\hline 4 & $1 \mathrm{c}$ & lipase CA & 53 & 0.92 & 2.3 \\
\hline 5 & $1 \mathrm{c}$ & lipase MM & 0 & & \\
\hline 6 & $1 \mathrm{c}$ & lipase PF & 0 & & \\
\hline $7^{\mathrm{c}}$ & $2 b$ & lipase $\mathrm{CA}$ & 94 & 4.8 & 2.4 \\
\hline 8 & $2 b$ & lipase MM & 0 & & \\
\hline 9 & $2 b$ & lipase PF & 0 & & \\
\hline 10 & $2 c$ & lipase CA & 40 & 0.45 & 2.3 \\
\hline 11 & $2 \mathrm{c}$ & lipase MM & 0 & & \\
\hline 12 & $2 c$ & lipase PF & 0 & & \\
\hline 13 & $2 d$ & lipase CA & 93 & 4.6 & 2.4 \\
\hline 14 & 2d & lipase MM & 0 & & \\
\hline 15 & $2 d$ & lipase PF & 4 & & \\
\hline 16 & $3 \mathbf{b}$ & lipase CA & 98 & 2.8 & 1.8 \\
\hline 17 & $3 b$ & lipase MM & 40 & 3.2 & 1.4 \\
\hline 18 & $3 b$ & lipase PF & 47 & 1.3 & 1.6 \\
\hline 19 & $4 b$ & lipase CA & 94 & 13 & 2.1 \\
\hline 20 & $4 b$ & lipase MM & 75 & 5.7 & 2.8 \\
\hline 21 & $4 b$ & lipase PF & 40 & 5.2 & 1.6 \\
\hline
\end{tabular}

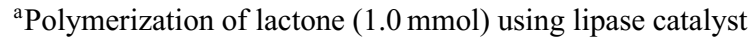
(50 mg) in bulk at $60{ }^{\circ} \mathrm{C}$ for $24 \mathrm{~h} .{ }^{\mathrm{b}}$ Determined by SEC. ${ }^{\mathrm{c}}$ Data from ref 9 .

ilar to that of $\gamma$-substituted lactone (2d) (entries 7 and 13). These data indicate that the polymerization behaviors depended on the substituted position of the lactone ring. ${ }^{1} \mathrm{H}$ and ${ }^{13} \mathrm{C}$ NMR analysis showed that the terminal structure of the polymer was of carboxylic acid at one end and of alcohol at the other terminal.

$\alpha$-Substituted macrolides ( $\mathbf{3 b}$ and $\mathbf{4 b}$ ) were polymerized by lipases CA, MM and PF (entries 16-21), and among them, the highest monomer conversion was observed in using lipase CA. The polyester with relatively high molecular weight was obtained from $\mathbf{4 b}$ using lipase CA catalyst (entry 19). These data indicate the high catalytic activity of lipase CA for the polymerization of the $\alpha$-substituted macrolides.

Comparison of Enzymatic Ring-Opening Polymerizability between Unsubstituted and Substituted Lactones

The polymerization behaviors of substituted lactones have been compared with those of unsubstituted lactones using lipase CA as catalyst (Table II). In the case of 6-membered lactones, the conversion of 1a was similar to that of $\mathbf{1 b}$ except the polymerization at $60^{\circ} \mathrm{C}$, which may be due to the equilibrium between the monomer and polymer in the polymerization of $\mathbf{1 b}$ at $60^{\circ} \mathrm{C}$ (entry 7). ${ }^{9}$ The lipase-catalyzed polymerization of 1a produced the polymer with relatively low molecular weight (entries 1-3), ${ }^{12}$ whereas the higher molec- 
Table II. Comparison of enzymatic polymerizability between unsubstituted and substituted lactones ${ }^{\mathrm{a}}$

\begin{tabular}{|c|c|c|c|c|c|c|c|c|}
\hline Entry & Monomer & Solvent ${ }^{b}$ & Enzyme & $\frac{\text { Temp. }}{{ }^{\circ} \mathrm{C}}$ & Time & Conv. $^{\mathrm{c}}$ & $\begin{array}{c}M_{\mathrm{n}}{ }^{\mathrm{c}} \\
10^{-3}\end{array}$ & $M_{\mathrm{w}} / M_{\mathrm{n}}^{\mathrm{c}}$ \\
\hline 1 & $1 \mathrm{a}$ & bulk & 50 & 35 & 8 & 73 & 1.2 & 2.1 \\
\hline 2 & $1 \mathrm{a}$ & bulk & 50 & 45 & 24 & 94 & 1.4 & 2.1 \\
\hline 3 & $1 a$ & bulk & 50 & 60 & 24 & 99 & 1.9 & 2.6 \\
\hline 4 & $1 b$ & bulk & 50 & 35 & 8 & 73 & 6.5 & 2.1 \\
\hline 5 & $1 b$ & bulk & 50 & 35 & 24 & 97 & 8.5 & 2.1 \\
\hline 6 & $1 b$ & bulk & 50 & 45 & 24 & 94 & 9.5 & 2.1 \\
\hline $7^{d}$ & $1 b$ & bulk & 50 & 60 & 24 & 74 & 11 & 1.9 \\
\hline 8 & $2 a$ & bulk & 10 & 35 & 2 & 47 & 3.2 & 3.1 \\
\hline 9 & $2 a$ & bulk & 10 & 45 & 2 & 55 & 3.7 & 3.2 \\
\hline 10 & $2 a$ & bulk & 10 & 60 & 2 & 57 & 4.5 & 3.0 \\
\hline 11 & $2 b$ & bulk & 10 & 35 & 2 & 45 & 1.4 & 1.8 \\
\hline 12 & $2 b$ & bulk & 10 & 45 & 2 & 47 & 1.3 & 1.9 \\
\hline 13 & $2 b$ & bulk & 10 & 60 & 2 & 62 & 1.7 & 2.1 \\
\hline 14 & 2d & bulk & 10 & 35 & 2 & 44 & 1.3 & 1.9 \\
\hline 15 & 2d & bulk & 10 & 45 & 2 & 48 & 1.4 & 1.8 \\
\hline 16 & 2d & bulk & 10 & 60 & 2 & 57 & 1.7 & 2.0 \\
\hline 17 & $3 \mathbf{a}$ & toluene & 10 & 45 & 2 & 60 & 4.9 & 3.0 \\
\hline 18 & $3 \mathbf{a}$ & toluene & 10 & 45 & 4 & 98 & 6.1 & 2.6 \\
\hline 19 & $3 b$ & toluene & 10 & 45 & 2 & 14 & 0.78 & 1.2 \\
\hline 20 & $3 \mathbf{b}$ & toluene & 10 & 45 & 4 & 41 & 2.0 & 2.3 \\
\hline 21 & $4 a$ & toluene & 10 & 45 & 0.5 & 41 & 5.0 & 3.3 \\
\hline 22 & $4 a$ & toluene & 10 & 45 & 1 & 94 & 10 & 2.7 \\
\hline 23 & $4 b$ & toluene & 10 & 45 & 2 & 28 & 3.5 & 1.9 \\
\hline 24 & $4 b$ & toluene & 10 & 45 & 4 & 62 & 4.7 & 1.9 \\
\hline
\end{tabular}

ular weight polymer was obtained from $\mathbf{1 b}$ under the similar reaction conditions (entries 4-7).

In the case of lactones of the ring size larger than seven, the smaller loading amount of lipase CA efficiently produced the polymer due to their higher enzymatic polymerizability than that of $\mathbf{1}$. Figure 1 shows time-conversion curves in the polymerization of 7 -membered lactones at $60^{\circ} \mathrm{C}$. It is to be noted that the polymerization rate of $\mathbf{2 a}, \mathbf{2} \mathbf{b}$, and $\mathbf{2 d}$ was close to each other, suggesting that $\alpha$ - and $\gamma$-substitution on the lactone ring scarcely affected the enzymatic polymerizability. The much lower polymerizability of $\mathbf{2 c}$ is probably due to the lower reactivity of the terminal secondary alcohol, which nucleophilically attacks onto the acyl carbon of the acyl-enzyme intermediate in the propagation stage. ${ }^{5 a}$ The molecular weight of poly(2a) was larger than that of the polymer from $\mathbf{2 b}$ or $\mathbf{2 d}$ under the similar reaction conditions (entries 8-16).

The polymers from unsubstituted macrolides are often highly crystalline; thus, the reaction rate much decreased in the latter stage of the bulk polymerization probably owing to the low diffusion of the monomer in the polymer matrix. ${ }^{13}$ Therefore, the polymerization of unsubstituted and substituted macrolides was performed in toluene for comparison of their enzymatic

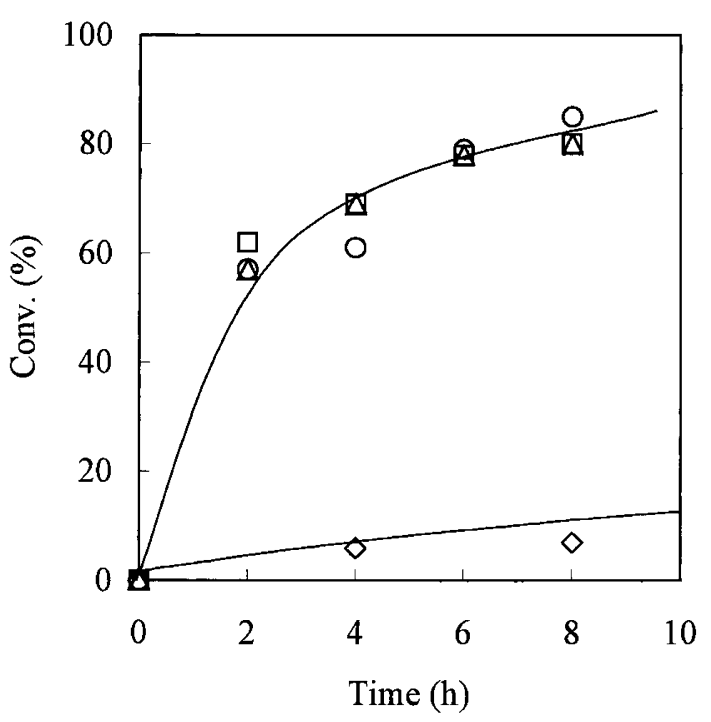

Figure 1. Time-conversion curves in the enzymatic polymerization of 7 -membered lactones $(2,1.0 \mathrm{mmol})$ using lipase CA $(10 \mathrm{mg})$ in bulk at $60^{\circ} \mathrm{C}:(\bigcirc) \mathbf{2 a} ;(\square) \mathbf{2 b} ;(\diamond) \mathbf{2 c} ;(\triangle) \mathbf{2 d}$.

polymerizability.

Figure 2 shows time-conversion curves in the lipase CA-catalyzed polymerization of 15-pentadecanolide (4a) and $4 \mathbf{b}$ in toluene at $45^{\circ} \mathrm{C}$. The reactivity of $\mathbf{4 b}$ was much smaller than that of $\mathbf{4 a}$. A similar behavior was observed in the polymerization of 13-membered 
lactones (3a and 3b) (entries 17-20). These behaviors are in contrast with those of the 7-membered lactones shown in Figure 1, suggesting that the enzymatic polymerizability strongly depended on the ring size and substituted position of the ring.

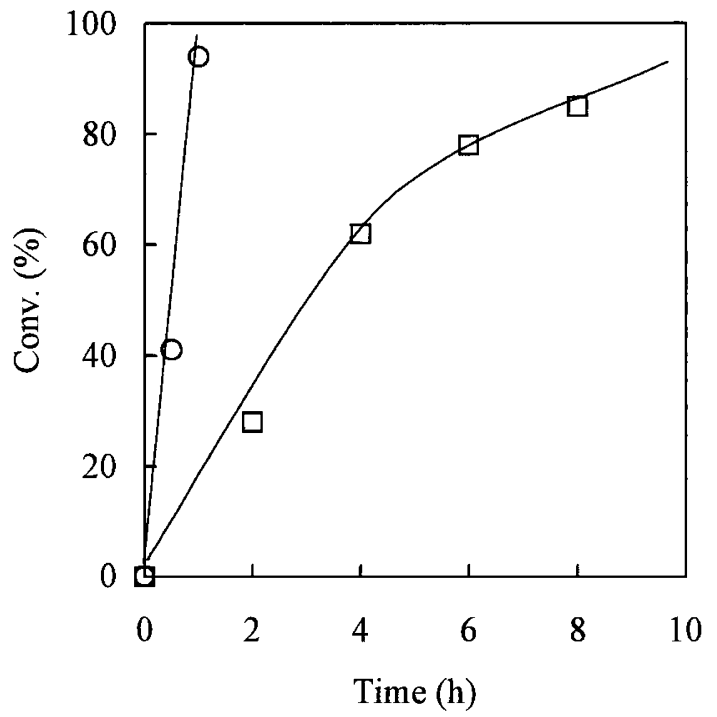

Figure 2. Time-conversion curves in the enzymatic polymerization of 16-membered lactones $(4,1.0 \mathrm{mmol})$ using lipase $\mathrm{CA}$ $(10 \mathrm{mg})$ in toluene $(2.5 \mathrm{~mL})$ at $45^{\circ} \mathrm{C}:(\bigcirc) \mathbf{4 a} ;(\square) \mathbf{4 b}$.

Comparison of Chemical and Enzymatic Polymerizability of Substituted Lactones

In cyclic compounds, reactivity is generally dependent upon their ring size; the ring strain of small and medium ring-size compounds is larger than that of macrocyclic ones, and hence, the former groups show higher ring-opening reactivity. In the case of unsubstituted lactones with ring size larger than six, the rate constant of the medium-size lactones in the chemical polymerization catalyzed by zinc octanoate was much larger than that of the macrolides, since the macrolides have much lower ring strain, and hence, show less polymerizability. ${ }^{4}$

In this study, the anionic polymerizability of lactones using sodium methoxide as initiator has been compared with that by the lipase catalyst. In all cases examined, the polyesters with molecular weight of several thousands were obtained and the polymerizability of $\alpha$ - and $\omega$-substituted lactones was lower than that of unsubstituted ones (Figure 3). In case of the 6- and 7-membered lactones, the $\omega$-substituted lactones possessed larger reactivity than the $\alpha$-substituted ones. This tendency was in reverse with that of the lipase-catalyzed polymerization (Table I). Interestingly, $\gamma$-substituted lactone (2d)

A)
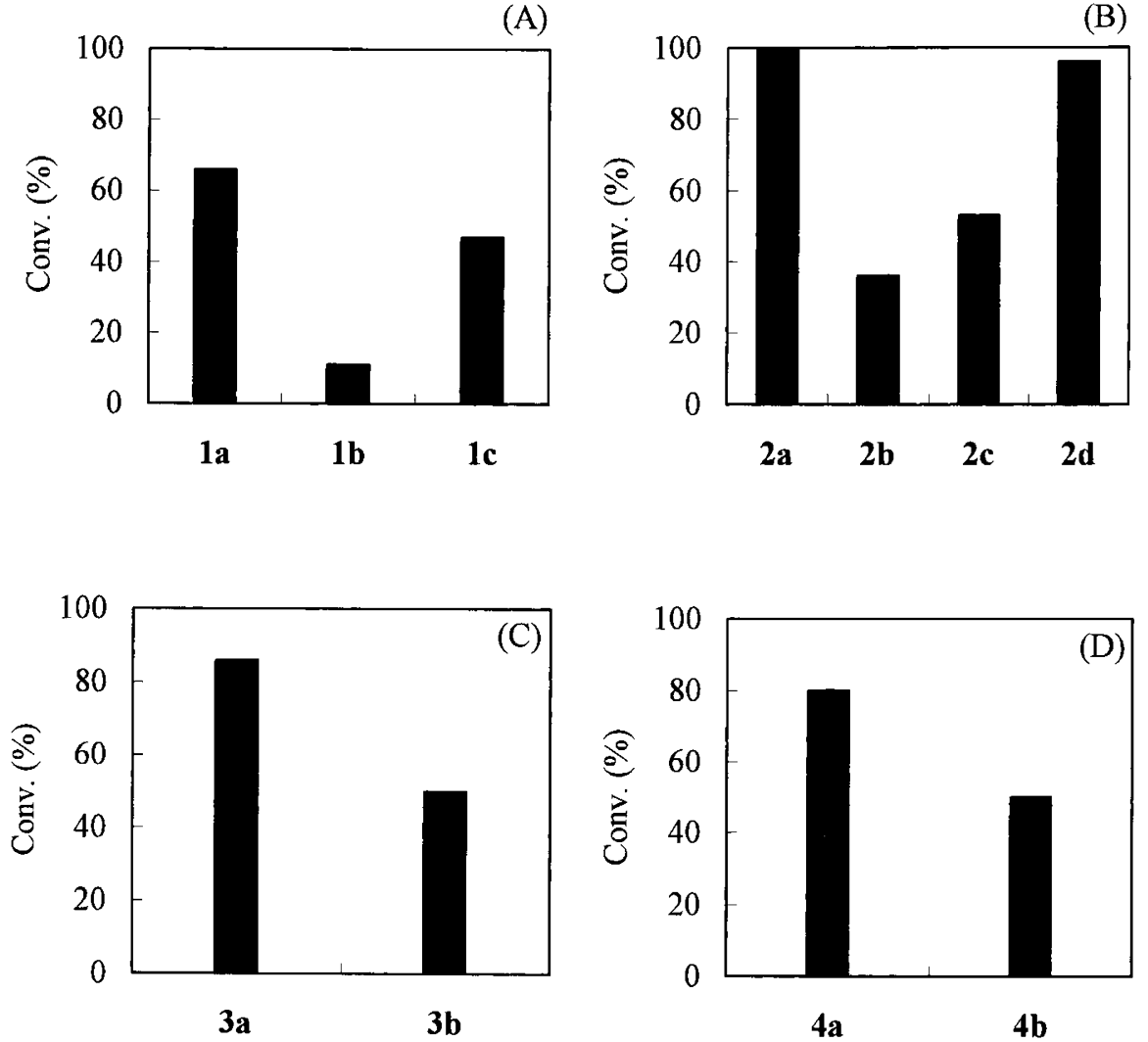

Figure 3. Effects of lactone structure on the monomer conversion in the anionic polymerization initiated by sodium methoxide $(6.0 \mathrm{~mol} \%$ for lactone) for $12 \mathrm{~h}$ : (A) polymerization of $\mathbf{1}$ in THF $(1.0 \mathrm{~mL})$ at $35^{\circ} \mathrm{C}$; (B) that of $\mathbf{2}$ in $\mathrm{THF}(1.0 \mathrm{~mL})$ at $25^{\circ} \mathrm{C}$; $(\mathrm{C})$ that of $\mathbf{3}$ in bulk at $100{ }^{\circ} \mathrm{C}$; (D) that of 4 in bulk at $100^{\circ} \mathrm{C}$. 
showed higher anionic polymerizability, as compared with that of $\mathbf{2 b}$ or $\mathbf{2 c}$.

As shown in Figures 1 and 3, the order of the polymerizability of the lactone monomers using lipase catalyst was different from that by anionic initiator; in case of the lactones with the $\omega$-substitution, the introduction of the substituent resulted in decrease of both anionic and enzymatic polymerizabilities, and the polymerization behaviors of $\alpha$-substituted lactones strongly depended on the ring size of lactones as well as type of catalyst (initiator).

\section{EXPERIMENTAL}

\section{Materials}

Solvents and unsubstituted lactones for enzymatic polymerization were commercially available and stored over freshly activated type 4 molecular sieves. THF for anionic polymerization was of anhydrous grade. $\alpha$ Methyl-substituted lactones (1) $\mathbf{1}, \mathbf{2 b}, \mathbf{3 b}$, and $\mathbf{4 b}$ ) were synthesized according to the literatures. ${ }^{14,15} \mathbf{1 c}, \mathbf{2 c}$, and $\mathbf{2 d}$ were prepared from the corresponding methylcycloalkanones by Baeyer-Villiger oxidation using $m$ chloroperoxybenzoic acid. ${ }^{16}$ Lipases CA and MM were kindly donated by Novozymes Japan Ltd. Lipases PF and $\mathrm{CC}$ were purchased from Biocatalysts. PPL was obtained from Sigma Chemical Co. All lipases were used without further purification.

\section{Enzymatic Polymerization}

A typical run was as follows (entry 19 in Table I). Lactone (4b, $250 \mathrm{mg}, 1.0 \mathrm{mmol})$ and lipase CA $(50 \mathrm{mg})$ were placed in a dried test tube under argon and sealed. The tube was kept at $60^{\circ} \mathrm{C}$ for $24 \mathrm{~h}$. THF $(10 \mathrm{~mL})$ was added and the part of the organic solution was separated by filtration. The solution was analyzed by SEC for the determination of the monomer conversion and polymer molecular weight. For NMR measurement, the solvent was removed under the reduced pressure and the residue was dried in vacuo. ${ }^{1} \mathrm{H}$ NMR of poly $(\mathbf{4 b})\left(\mathrm{CDCl}_{3}\right) \delta 1.1\left(\mathrm{~d}, \mathrm{CHCH}_{3} \mathrm{C}(=\mathrm{O})\right), 1.2-1.7$ (m, $\left.\mathrm{OCH}_{2}\left(\mathrm{CH}_{2}\right)_{12} \mathrm{CH}\left(\mathrm{CH}_{3}\right)\right), 2.4\left(\mathrm{~m}, \mathrm{CHCH}_{3} \mathrm{C}(=\mathrm{O})\right)$, $3.6\left(\mathrm{t}, \mathrm{CH} \mathrm{H}_{2} \mathrm{OH}\right), 4.0\left(\mathrm{t}, \mathrm{CH}_{2} \mathrm{OC}(=\mathrm{O})\right) ;{ }^{13} \mathrm{C} \mathrm{NMR}$ $\left(\mathrm{CDCl}_{3}\right) \delta 17\left(\mathrm{CH}\left(\mathrm{CH}_{3}\right) \mathrm{C}(=\mathrm{O}),\right)$ ) 25-34 $\left(\mathrm{OCH}_{2}\left(\mathrm{CH}_{2}\right)_{12}\right.$ $\left.\mathrm{CH}\left(\mathrm{CH}_{3}\right)\right), 40\left(\mathrm{CH}\left(\mathrm{CH}_{3}\right) \mathrm{C}(=\mathrm{O})\right), 64\left(\mathrm{CH}_{2} \mathrm{OC}(=\mathrm{O})\right)$, $\left.177(C(=)) \mathrm{OCH}_{2}\right)$.

\section{Anionic Polymerization}

A typical run was as follows. To dry THF solution $(1.0 \mathrm{~mL})$ containing in situ prepared sodium methoxide $\left(3.2 \mathrm{mg}, 6.0 \times 10^{-2} \mathrm{mmol}\right)$, lactone $(2 \mathbf{b}, 130 \mathrm{mg}$, $1.0 \mathrm{mmol}$ ) was added under argon at $25^{\circ} \mathrm{C}$ under gentle stirring. After $12 \mathrm{~h}$, the polymerization was terminated by the addition of a small amount of $\mathrm{HCl}$ methanol solution. After evaporation of the solvent under reduced pressure, THF was added to the mixture. The THFsoluble part was separated by filtration and used for SEC analysis.

\section{Measurements}

SEC analysis was carried out by using a Tosoh SC8010 apparatus equipped with refractive index (RI) detector at $40{ }^{\circ} \mathrm{C}$ under the following conditions: TSKgel G3000 $\mathrm{H}_{\mathrm{HR}}$ column and THF eluent at a flow rate of $1.0 \mathrm{~mL} \mathrm{~min}^{-1}$. The calibration curves were obtained using polystyrene standards. NMR spectra were recorded on a Bruker DPX400 spectrometer.

Acknowledgments. This work was partly supported by Program for Promotion of Basic Research Activities for Innovative Bioscience and by Program of Precision Polymer Technology, JCII and AIST, Japan. We acknowledge the gift of lipases $\mathrm{CA}$ and $\mathrm{MM}$ from Novozymes Japan Ltd.

\section{REFERENCES}

1. a) D. B. Johns, R. W. Lenz, and A. Luick, in "Ring-Opening Polymerization", K. J. Ivin and T. Saegusa, Ed., Elsevier Applied Science Publishers, London, 1984, vol. 1, chapt. 7.

b) R. Jérôme and P. Teyssié, in "Comprehensive Polymer Science", G. C. Eastmond, A. Ledwith, S. Russo, and P. Sigwalt, Ed., Pergamon Press, Oxford, 1989, vol. 3, part 1, chapt. 34.

2. For recent reviews on enzymatic synthesis of polyesters, see: a) S. Kobayashi, S. Shoda, and H. Uyama, Adv. Polym. Sci., 121, 1 (1995).

b) S. Kobayashi, S. Shoda, and H. Uyama, in "Catalysis in Precision Polymerization”, S. Kobayashi, Ed., John Wiley \& Sons Ltd., Chichester, 1997, chapt. 8.

c) R. A. Gross, D. L. Kaplan, and G. Swift, ACS Symposium Series, No. 684, American Chemical Society, Washington, D.C., 1998.

d) S. Kobayashi and H. Uyama, in "Materials Science and Technology-Synthesis of Polymers", A.-D. Schlüter, Ed., Wiley-VCH, Weinheim, 1998, chapt. 16.

e) S. Kobayashi and H. Uyama, in "Biopolyesters", W. Babel and A. Steinbüchel, Ed., Springer-Verlag GmbH \& Co., Heidelberg, 2001, pp 241-262.

f) S. Kobayashi, H. Uyama, and M. Ohmae, Bull. Chem. Soc. Jpn., 74, 613 (2001).

g) R. A. Gross, A. Kumar, and B. Kalra, Chem. Rev., 101, 2097 (2001).

h) S. Kobayashi, H. Uyama, and S. Kimura, Chem. Rev., 101, 3793 (2001).

i) R. A. Gross, B. Karla, and A. Kumar, Appl. Microbiol. Biotechnol., 55, 655 (2001).

j) S. Kobayashi and H. Uyama, in "Biopolymers. Vol. 3: Polyesters (Part A)”, A. Steinbüchel, Ed., Wiley-VCH, Weinheim, 2001, pp 373-400. 
k) S. Kobayashi and H. Uyama, Curr. Org. Chem., 6, 209 (2002).

1) S. Matsumura, Macromol. Biosci., 2, 105 (2002).

m) S. Kobayashi and H. Uyama, in "Encyclopedia of Polymer Science and Technology”, 3rd ed, J. I. Kroschwitz, John Wiley \& Sons, Inc., New York, N.Y., 2001.

3. For recent papers on enzymatic ring-opening polymerization of lactones, see:

a) H. Nishida, M. Yamashita, M. Nagashima, T. Endo, and Y. Tokiwa, J. Polym. Sci., Polym. Chem. Ed., 38, 1560 (2000).

b) A. Kumar and R. A. Gross, Biomacromolecules, 1, 133 (2000).

c) A. Kumar, B. Kalra, A. Dekhterman, and R. A. Gross, Macromolecules, 33, 6303 (2000).

d) S. Namekawa, H. Uyama, and S. Kobayashi, Macromol. Chem. Phys., 202, 801 (2001).

e) A. Kumar, K. Garg, and R. A. Gross, Macromolecules, 34, 3527 (2001).

f) H. Ebata, K. Toshima, and S. Matsumura, Chem. Lett., 798 (2001).

g) H. Uyama, S. Kobayashi, M. Morita, S. Habaue, and Y. Okamoto, Macromolecules, 34, 6554 (2001).

h) A. Córdova, Biomacromolecules, 2, 1347 (2001).

4. A. Duda, A. Kowalski, S. Penczek, H. Uyama, and S. Kobayashi, Macromolecules, 35, 4266 (2002).

5. a) H. Uyama, K. Takeya, and S. Kobayashi, Bull. Chem. Soc. Jpn., 68, 56 (1995).

b) H. Uyama, K. Takeya, N. Hoshi, and S. Kobayashi, Macromolecules, 28, 7046 (1995).

c) H. Uyama, S. Namekawa, and S. Kobayashi, Polym. J., 29, 299 (1997).

d) S. Kobayashi, H. Uyama, S. Namekawa, and H. Hayakawa, Macromolecules, 31, 5655 (1998).

e) S. Kobayashi, H. Uyama, and S. Namekawa, Polym. Degrad. Stab., 59, 195 (1998).

f) S. Namekawa, H. Uyama, and S. Kobayashi, Proc. Jpn. Acad. Ser. B, 74, 65 (1998).

g) S. Namekawa, S. Suda, H. Uyama, and S. Kobayashi, Int.
J. Biol. Macromol., 25, 145 (1999).

h) S. Kobayashi and H. Uyama, Macromol. Symp., 144, 237 (1999).

6. a) G. A. R. Nobes, R. J. Kazlauskas, and R. H. Marchessault, Macromolecules, 29, 4829 (1996).

b) Y. Y. Svirkin, J. Xu, R. A. Gross, D. L. Kaplan, and G. Swift, Macromolecules, 29, 4591 (1996).

c) S. Namekawa, H. Uyama, and S. Kobayashi, Polym. J., 28, 730 (1996).

d) W. Xie, J. Li, D. Chen, and P. G. Wang, Macromolecules, 30, 6997 (1997).

e) H. Kikuchi, H. Uyama, and S. Kobayashi, Macromolecules, 33, 8971 (2000).

f) S. Matsumura, Y. Suzuki, K. Tsukada, K. Toshima, Y. Doi, and K. Kasuya, Macromolecules, 31, 6444 (1998).

g) Y. Osanai, K. Toshima, and S. Matsumura, Macromol. Biosci., 1, 171 (2001).

7. H. K. Hall, Jr. and A. K. Schneider, J. Am. Chem. Soc., 80, 6409 (1958).

8. J.-M. Vion, R. Jérôme, and P. Teyssié, Macromolecules, 19, 1828 (1986).

9. K. Küllmer, H. Kikuchi, H. Uyama, and S. Kobayashi, Macromol. Rapid Commun., 19, 127 (1998).

10. M. Runge, D. O'Hagan, and G. Haufe, J. Polym. Sci., Part A: Polym. Chem., 38, 2004 (2000).

11. H. Uyama, S. Suda, H. Kikuchi, and S. Kobayashi, Chem. Lett., 1109 (1997).

12. a) H. Uyama and S. Kobayashi, Chem. Lett., 1149 (1993). b) S. Kobayashi, K. Takeya, S. Suda, and H. Uyama, Macromol. Chem. Phys., 199, 1729 (1998).

13. H. Uyama, H. Kikuchi, K. Takeya, and S. Kobayashi, Acta Polym., 47, 357 (1996).

14. J. L. Herrmann and R. H. Schlessinger, J. Chem. Soc., Chem. Comm., 711 (1973).

15. K. Tsushima, K. Araki, and A. Murai, Chem. Lett., 1313 (1989).

16. E. Fouque and G. Rousseau, Synthesis, 661 (1989). 